\title{
Protection that tastes good
}

When you have patients with problem areas in their teeth that need an extra level of protection, a tooth varnish is an excellent option.

So why not chose a varnish that offers excellent protection and that tastes good as well?

Clinpro White Varnish from 3M Oral Care is not only a virtually invisible solution, but also an effective combative against hypersensitivity. Now available in a range of flavours including delicious cherry, mint and melon, Clinpro White Varnish from $3 \mathrm{M}$ is patient friendly and will help them protect their teeth without leaving a nasty taste in their mouth.

Prevention is key - so contact $3 \mathrm{M}$ on 0800 626578 or visit www.3m.co.uk/Dental.

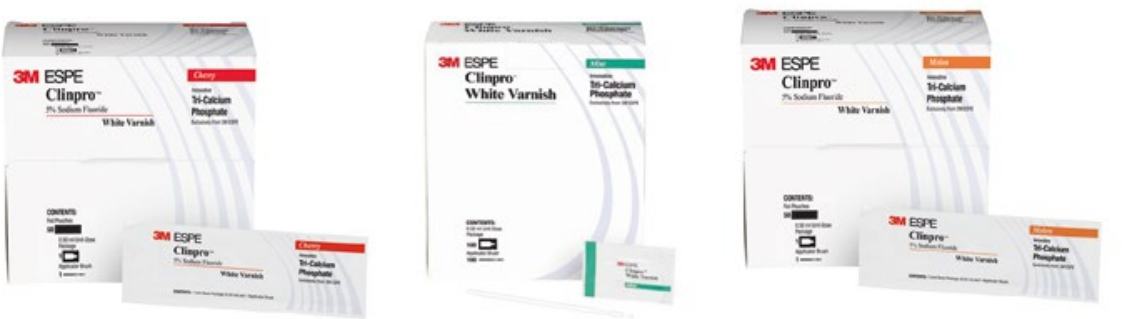

\section{8 years of smiles}

TANDEX celebrated its 88 th birthday this year. That's 88 years of developing and supplying high-quality oral hygiene products to dental professionals and patients. In that time we haven't changed our core values either.

TANDEX wants to spread the message that preventing decay can be fun, with the right tools! We are committed to using the best raw materials and listening to what people want. Our range includes solutions for daily brushing as well as interdental brushing, like the TANDEX FLEXI, PREVENT GEL and WASH \& PREVENT mouthwash.
Try the TANDEX difference - and here's to another 88 years of smiles!

For more information on Tandex's range of products, visit www.tandex.dk or visit the Facebook page: www.facebook.com/pages/ Tandex-UK/234855250044190?fref=ts.

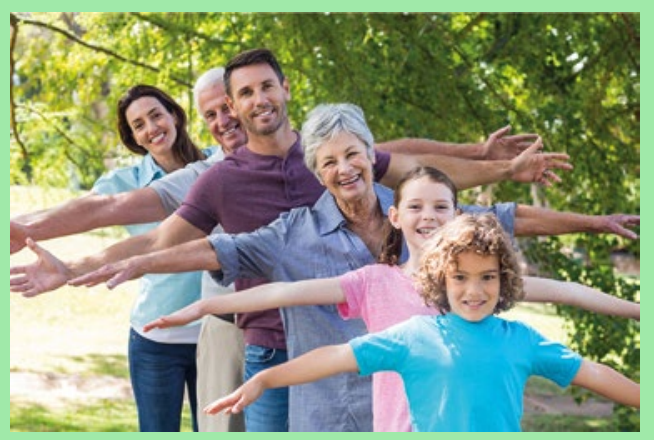

Gold standard disease prevention

The CALCIVIS imaging system provides reliable visual evidence of early active demineralisation on the surfaces of the teeth.

$\rightarrow$ CALCIVIS helps you to detect very early carious lesions in time to begin noninvasive treatment and prevent disease progression

$\rightarrow$ CALCIVIS can change your patients' attitudes towards dentistry and demonstrate your commitment to the preventive, minimally-invasive approach

$\rightarrow$ CALCIVIS provides engaging, high quality oral health education that motivates patients to improve their oral hygiene and reduce the chances of invasive treatments in the future

$\rightarrow$ CALCIVIS adds value to dental examinations and has the potential to grow your bottom line.

For more information visit www. calcivis.com, call on 01316585152 or email at info@calcivis.com.

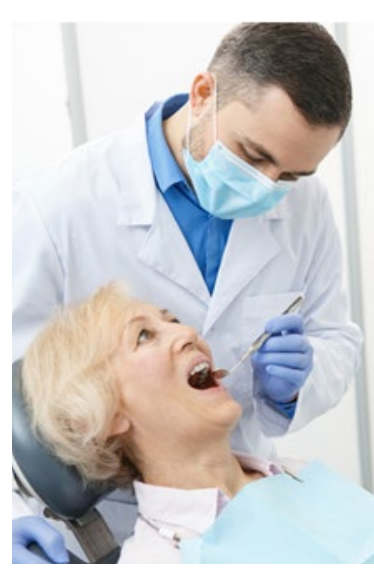

\section{Slide your patients towards better oral health}

Ergonomically designed with an easy grip handle, the Wisdom Clean Between Easy Slide Tensioning Flossers with PTFE tape make maintaining oral health simple for patients.

The innovative Waveform Tension Control System holds the tape taunt to facilitate smooth movement between the teeth. Not only does this promote optimal patient comfort, but it also gives them total control for a more effective and less traumatic interdental clean.

Easy to use, even for those with poorer dexterity, the Wisdom Clean Between Easy Slide Tensioning Flossers slide easily between the teeth to make effective interdental cleaning possible for more of your patients.

Visit www.wisdomtoothbrushes.com or call 01440714800 .

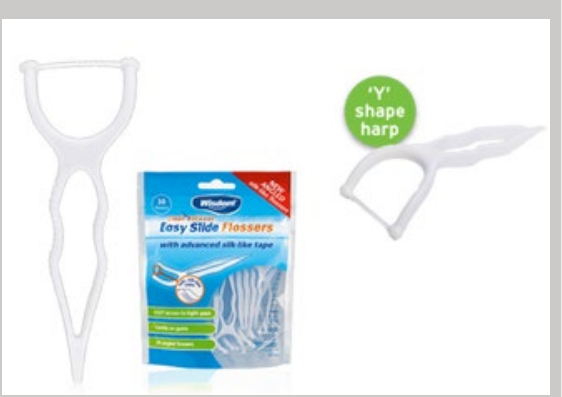

